\title{
Apprentice Distiller Fatally Burned by Overpressurized Pot Still
}

\section{Incident Number: 15KY019}

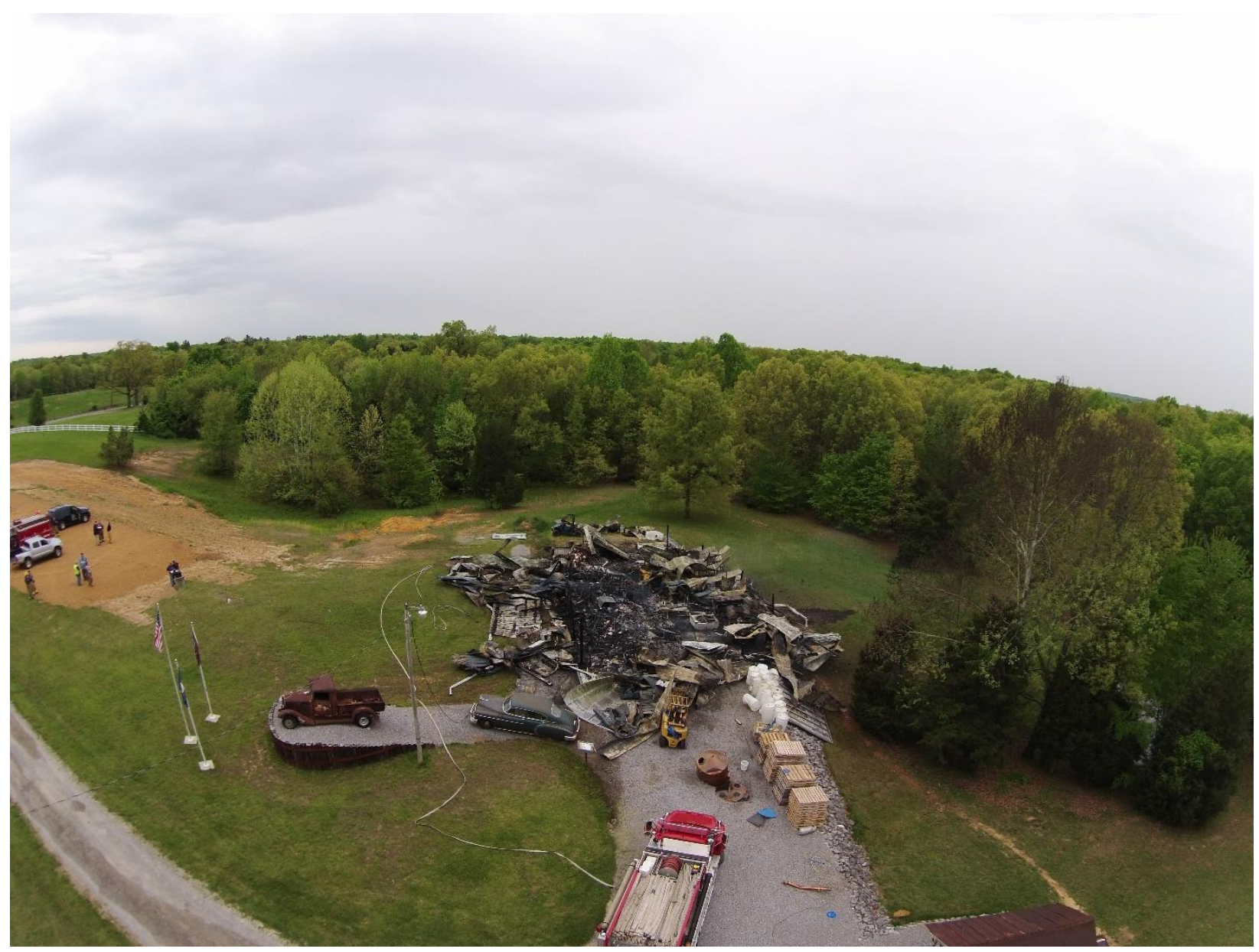

Photo courtesy of Marshall County Daily Newspaper

Kentucky Fatality Assessment and Control Evaluation Program Kentucky Injury Prevention and Research Center 333 Waller Avenue Suite 242

Lexington, Kentucky 40504

Phone: 859-323-2981

Fax: 859-257-3909

www.kiprc.uky.edu

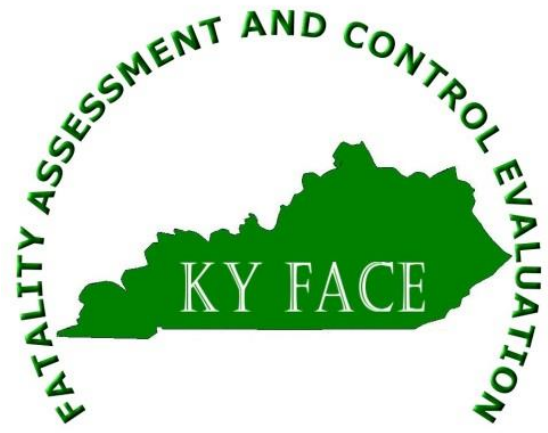




\section{Kentucky Fatality Assessment and Control Evaluation (FACE) Program \\ Incident Number: 15KY019 \\ Release Date: December 15, 2015 \\ Subject: Apprentice Distiller Fatally Burned by Overpressurized Pot Still}

\section{$\underline{\text { Introduction }}$}

Friday, April 24, 2015, a 40-year-old distiller and a 27-year-old distiller apprentice (victim) were producing a batch of moonshine when the Revenoor 300 gallon pot still unexpectedly ruptured. The distiller said he heard a noise like a car backfiring and he and the victim were knocked to the ground covered in $200^{\circ}$ Fahrenheit mash (mixture of grain and water used in distilling). The distillery owner heard a loud pop from his home, ran to the distillery and found both employees outside and injured. After turning off the propane, the owner brought both employees to his home where his wife called emergency fire and medical services. The two employees were conscious and airlifted to the nearest trauma burn center. The victim died 17 days later on May 11,2015 , from complications due to infection resulting from the burns.

To prevent future occurrences of similar incidents, the following recommendations have been made:

Recommendation No. 1: Batch distillation system manufacturers should ensure that an appropriate rated temperature and relief pressure valve be installed on manufactured pot stills.

Recommendation No. 2: Pre-job hazard analysis should include regular inspection of the distilling column for buildup.

Recommendation No. 3: Distilleries should consider installation of fire foam protection systems and installation of emergency showers.

Recommendation No. 4: Legislative bodies should consider passage and implementation of state regulations that require routine inspection of stills by a competent person in distillery businesses. 


\section{$\underline{\text { Employer }}$}

The employer was a small distillery with nine employees. They opened for business July 2011, and joined the Kentucky Distillers Association in 2012. The employer distills legal moonshine and has won several awards.

\section{Written Safety Programs and Training}

The employer had written safety programs that were reviewed with each employee upon hiring. The training was on-the-job training that included equipment inspection, pot still inspection and operation, safe bottling, and emergency response. The pot still was inspected before and after each run to detect any leaks, and was filled nightly before operation.

\section{$\underline{\text { Victim }}$}

The fatally injured victim was a 27 -year-old college graduate who was proud of his job and was training to be the $3^{\text {rd }}$ master distiller at the site. He was officially in his third week of work. The on-the-job training to be a certified master distiller requires at least one year of hands-on training, while being closely supervised by another master distiller. The other non-fatally injured victim was the second master distiller.

\section{$\underline{\text { Incident Scene }}$}

The incident scene was a metal-sided pole barn measuring $40 \mathrm{ft}$ x $60 \mathrm{ft}$ that housed several pot stills for distilling moonshine. The building was located 1,500 feet behind the owner's home, high on a flat hilltop. The building was constructed in 1998. At the time of the incident, there were 5-6 pallets containing 60 cases of finished product along with several barrels of mash.

\section{$\underline{\text { Equipment }}$}

The equipment was a Revenoor 300 pot still with a reflux tower (see photo \#1). This particular pot still was newly ordered in December 2011, and installed at the location in September 2012. According to the manufacturer's website, the pot still was designed with a solid copper temperature-controlled tower for added efficiency. The still had a heavy duty, treated steel cooker and a solid copper detachable column with silver soldered fittings. Each still is built with a safety valve which can be activated by less than one pound of pressure. The still has a water cooled condenser and 2 built in thermometers. The temperature operations are from 173 to 210 degrees Fahrenheit. The still was $12 \mathrm{ft} 4$ inches in height and came with a one-year warranty.

The owner stated the pot still was originally ordered with electric heating elements, but the distiller fueled the pot still with propane gas. The pot still sat on a base that housed 4 burners, and a ventilation fan pushed combustion gas to the exterior of the building through vent pipes. The base was $6 \mathrm{ft}$ long and $5 \mathrm{ft}$ wide, and was covered with sheet metal with a circular opening measuring $3 \mathrm{ft} 10$ inches, exposing 4 burners that directly fired the still. The pot still had a needle 
valve to control output; a thermometer measured the temperature of the pot still. Normal operating temperature was 200-204 degrees Fahrenheit.

The owner stated that three years prior to this event, the second time the still was operated, a split occurred in the side wall seam where the side wall connected to the pot bottom next to a drain. The manufacturer was contacted for advice on repair of the split. A professional welder silversoldered the split in the seam with a Tungsten Inert Gas (TIG) weld.

\section{Weather}

April 24, 2015, was a clear sunny day with temperatures ranging from 42 to 64 degrees Fahrenheit. Weather was not considered a factor in this fatality.

\section{$\underline{\text { Investigation }}$}

The Kentucky Labor Cabinet notified the Kentucky Fatality Assessment and Control Evaluation (FACE) Program of a fatality involving a burn victim from an explosion that occurred April 24, 2015. An investigation was conducted.

April 24, 2015 was a normal day at the distillery. The owner, a master distiller, walked from his home to the distillery in his back lot and lit the propane burner for the 300 gallon pot still at 7:00 am. It typically took 2-3 hours for the pot still to reach production temperature. The owner stated that the employees arrived to work later than normal because of an event attended the night before that ran late. The owner stayed with the pot still until the first employee, the second master distiller, arrived around 8:30 am. Once the second master distiller arrived, the owner walked back to his home.

Only two employees were scheduled to work the day of the incident, and the victim arrived at 9:30 am. He was in his third official week of on-the-job training but he had worked unpaid for two weeks prior shadowing the second master distiller, then deciding that that he wanted to become a master distiller.

On the morning of the incident, the two employees had the left side metal door open $6 \mathrm{ft}$. wide. The second master distiller walked the victim through the morning routine of checking both pot stills. The employees then lit a smaller 188 gallon still. They were producing a batch of moonshine with the smaller still once the 300 gallon still finished its run. The 300 gallon still was at 199 degrees Fahrenheit and began producing finished product. The still had reached a point where the employees pulled off the first gallon of moonshine and discarded it. This was normal procedure. They pulled the next three gallons and set it off to the side.

The second master distiller was approximately five feet from the 300 gallon still, with his back to the still, speaking to the victim. Without warning, they heard a noise similar to a car backfiring and they were both thrown to the ground and covered in hot mash. The second master distiller said he heard things popping behind him. He believed they were the bottles of moonshine they had pulled off the still. Shocked and confused, he got up and helped the victim exit the building. 
At this time there was no major fire inside the distillery. The large 10x10 metal door of the building was bent and pushed outward.

As they exited the building covered in hot mash, the second master distiller found the 300 gallon still and some of its components outside the building in the driveway, next to the distillery, and 90 feet from where the still had been mounted in the building.

As the owner ran toward the distillery, the second master distiller yelled for him to turn off the main source of propane. When the owner turned off the propane, he noticed a green haze hanging in the air and flaming mash running down the interior walls of the building. Not knowing if he could extinguish the flames with his fire extinguisher, he exited. He walked his employees to his home. The green haze was a concentration of vapors from the alcohol that eventually caught fire inside the building.

Both of the employees were covered in 200 degree hot mash. The owner's wife immediately dialed the fire department and requested emergency medical crews as well. The call came into dispatch at 10:32 am and crews arrived on the scene at 10:43 am. A total of four fire departments responded to this incident. By the time the first fire department arrived on scene, smoke and flames were visible. Even though four fire departments fought the fire, the building burned to the ground.

The victim had managed to walk to the owner's home and was sitting on the steps with a bottle of water, while the second master distiller began to experience shock and laid down in the driveway. Both workers were covered with 200 degree Fahrenheit mash over the majority of their bodies. The second master distiller stated he thought the victim also received burns from exploding bottles of moonshine, because he was injured more severely. Emergency crews worked on victims until medical helicopters arrived at 11:38 am to transport them to a nearby trauma burn center. Both the second master distiller and the victim were conscious during the flight to the hospital. The second master distiller had third degree burns on $80 \%$ of his body and the victim suffered third degree burns to $86 \%$ of his body. The victim died 17 days later on May 11,2015 , from complications due to infection resulting from the burns.

\section{Cause of Death}

The cause of death was due to complications from infection of third degree burns to $86 \%$ of the body.

\section{$\underline{\text { Recommendations and Discussions }}$}

\section{Recommendation No. 1: Batch distillation system manufacturers should ensure that an appropriate rated temperature and relief pressure valve be installed on manufactured pot stills.}

The investigation revealed the rating on the temperature and pressure relief valve did not match the documentation shipped with the still. The document stated "the stills are built with a safety 
valve that operated on less than 1 psi of pressure." However, the valve installed on the still was a Watts Model LLL100X1 with a 150 psi and 210 degrees Fahrenheit rating. The valve needed to have a lower psi rating as well as a lower degree rating to ensure the integrity of the still during over pressurization. Pressure could have built up in the still without the employees' knowledge since they relied on the temperature and pressure relief valve to release pressure if necessary. An appropriate rated temperature and pressure relief valve may have prevented the event. It should also be noted the Watts Model LLL100X1 valve is listed for use only in water heaters.

The State Fire Marshal's report stated that the setting on the pressure relief valve was different from the setting in the manufacturer specifications. The valve (see photo \#3) should have been set to $\sim 15$ psi but was equipped with a 150 psi pressure relief valve. With a 150 psi valve, the still could become overpressurized, causing the still to rupture and mash to erupt (see photo \#5). The manufacturer told the Fire Marshall that the pressure relief valve was a backup in case the output on the still became blocked.

\section{Recommendation No. 2: Pre-job hazard analysis should include inspection of the distilling column for buildup.}

According the State Fire Marshall report, the still discharge could have become blocked causing catastrophic failure. Over packing the column with glass balls or a buildup of mash in the column could lead to unintentional over pressurization.

The State Fire Marshall's report ultimately recommended that "1) listed pressure relief valves should be installed in the vapor space of the pot and column with the discharge remotely piped to the exterior of the building; and 2) pressure gauges should be installed in the vapor space of the of the pot and the column."

\section{Recommendation No. 3: Distilleries should consider installation of fire foam protection systems and installation of emergency showers. ${ }^{1}$}

In the event of a fire, distilleries should be equipped with foam protection systems. Alcohol resistant foam creates a barrier between the liquid and the atmosphere. If the employer had this system in place, the foam could have smothered the mash and flames and prevented the concentrated vapors from catching fire and burning the entire building.

Emergency showers similar to those found in chemical labs could have been used to wash the hot mash off the exposed employees when the still ruptured. The showers could also be equipped with an eye wash station that would be useful if mash were to splatter into a worker's eyes during a rupture.

Recommendation No. 4: Legislative bodies should consider passage and implementation of state regulations that require routine inspection of stills by a competent person in distillery businesses. 
Mandating routine safety inspections of stills may have prevented this incident. An inspection would likely have discovered the pressure release valve was not the correct valve for the still or over packing of the column with glass balls could cause too much pressure to build leading to a rupture.

\section{$\underline{\text { Keywords }}$}

Fire

Mash

Moonshine

Stills

Distilleries

Explosions

\section{References}

${ }^{1}$ Recommended Fire Protection Practices for Distilled Spirits Beverage Facilities. Third edition. The Distilled Spirits Council of the United States, Inc. Print.

\section{Acknowledgements}

The Kentucky FACE program would like to thank the State Fire Marshall's office, the distillery owner, and the surviving employee for their assistance with this report.

The Kentucky Fatality Assessment \& Control Evaluation Program (FACE) is funded by grant 2U600H008483-11 from the Centers for Disease Control and Prevention and the National Institute for Occupational Safety and Health. The purpose of FACE is to aid in the research and prevention of occupational fatalities by evaluating events leading to, during, and after a work related fatality. Recommendations are made to help employers and employees have a safer work environment. For more information about FACE and KIPRC, please visit our website: www.mc.uky.edu/kiprc/programs/face.html 


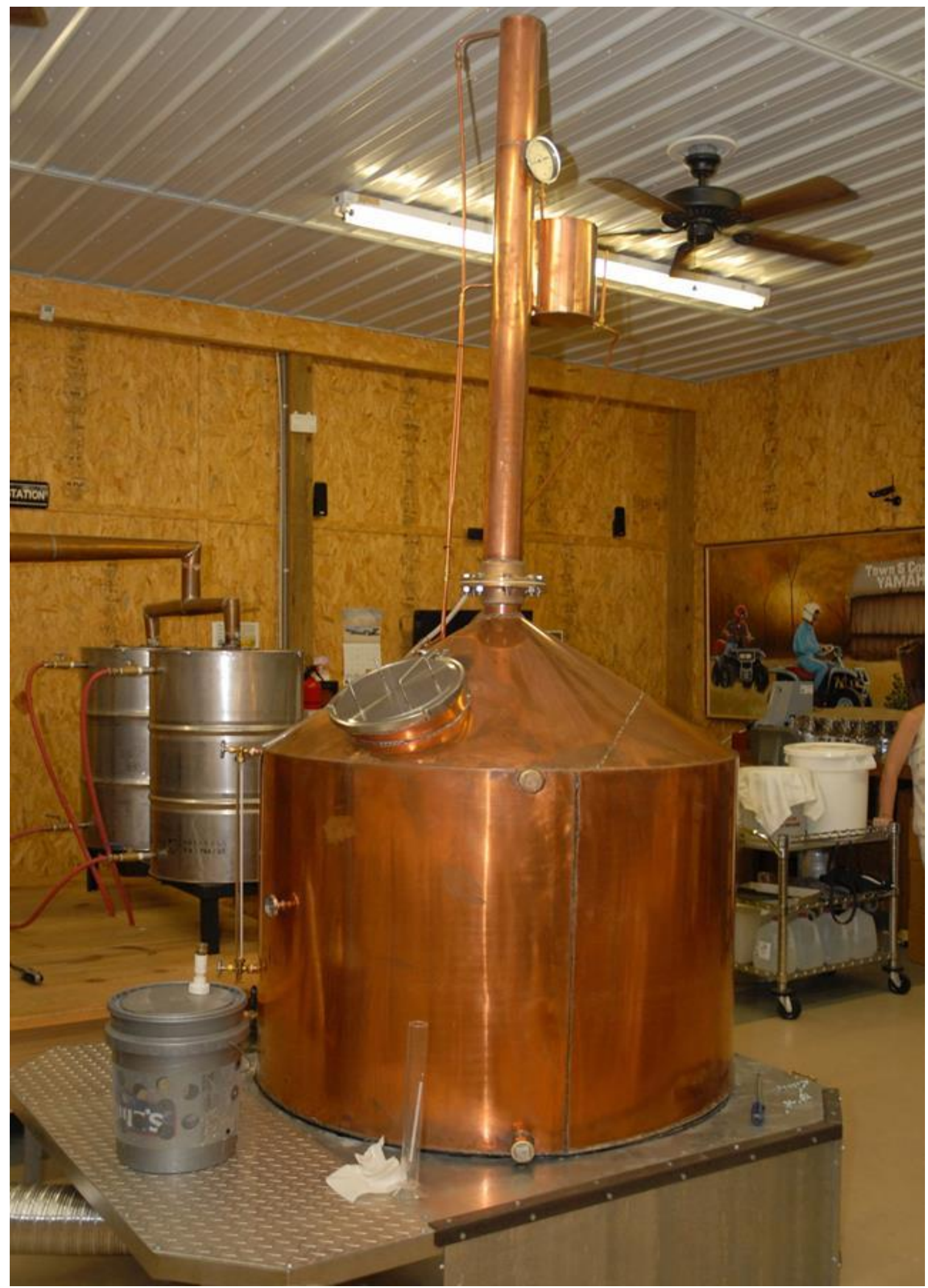

Photo \#1: The actual still prior to incident. (Photo courtesy of the employer) 


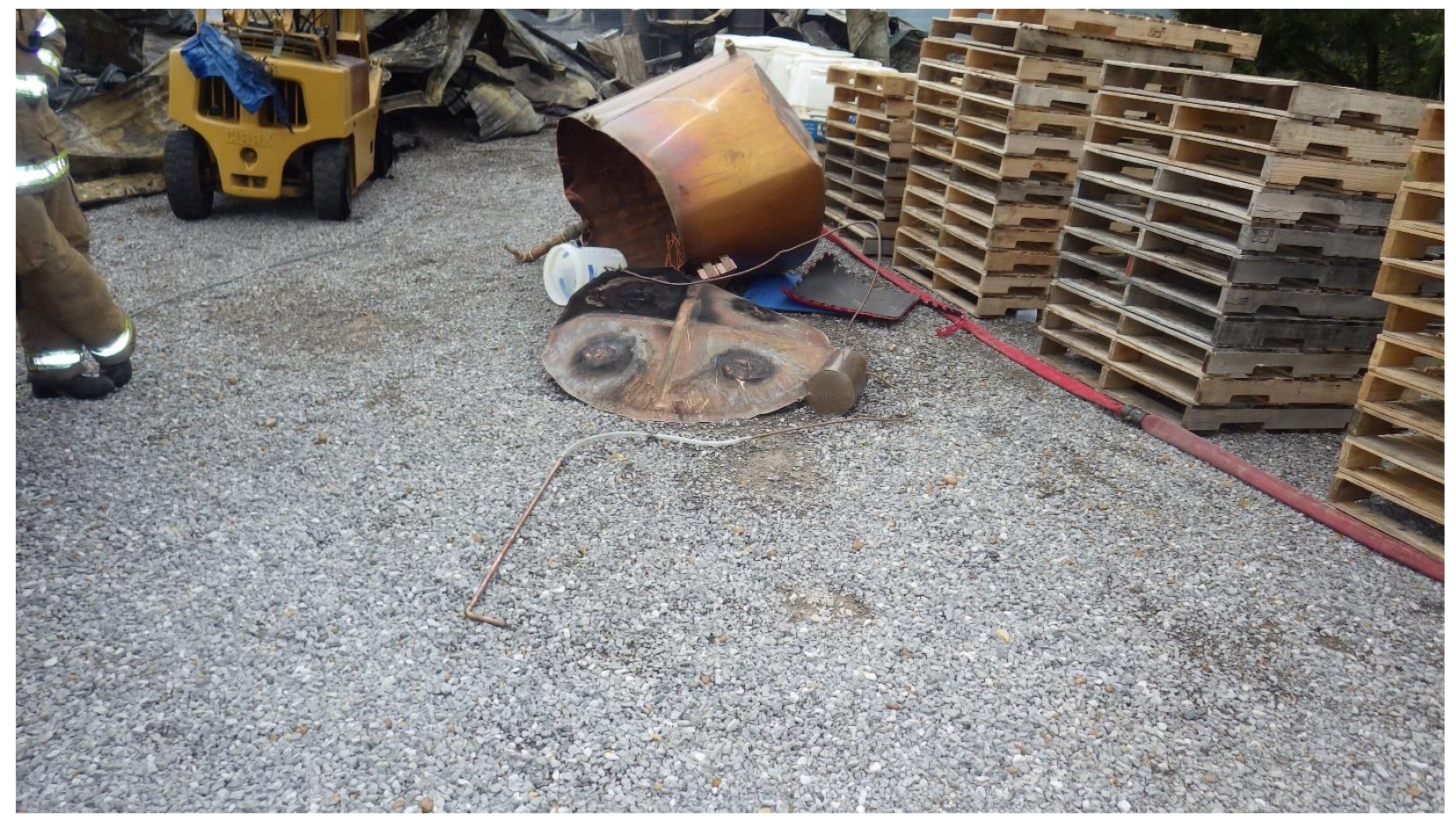

Photo \#2: The still in the driveway. (Photo courtesy of the State Fire Marshall) 


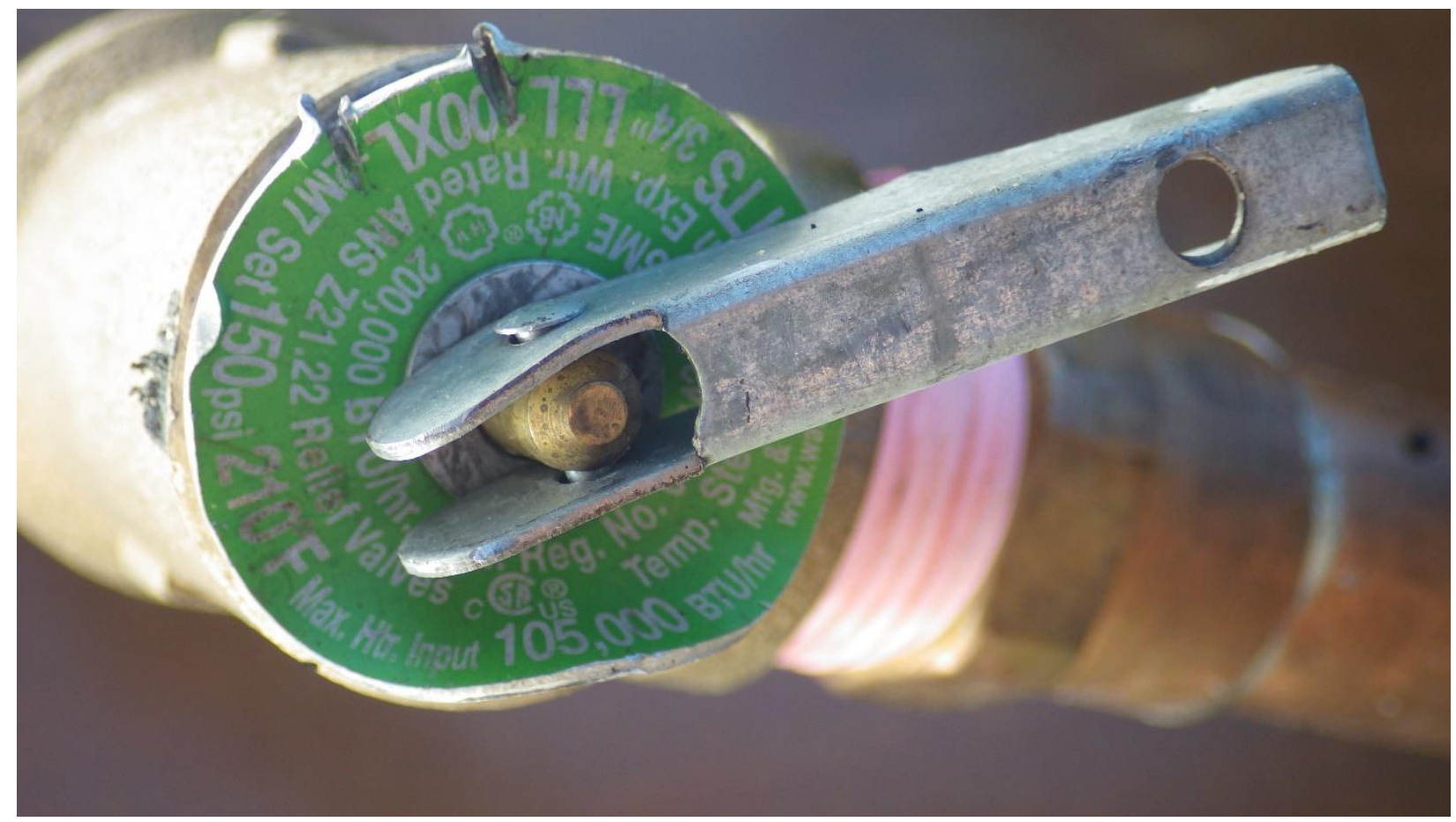

Photo \#3: The PSI of the temperature and pressure relief valve. (Photo courtesy of State Fire Marshall)

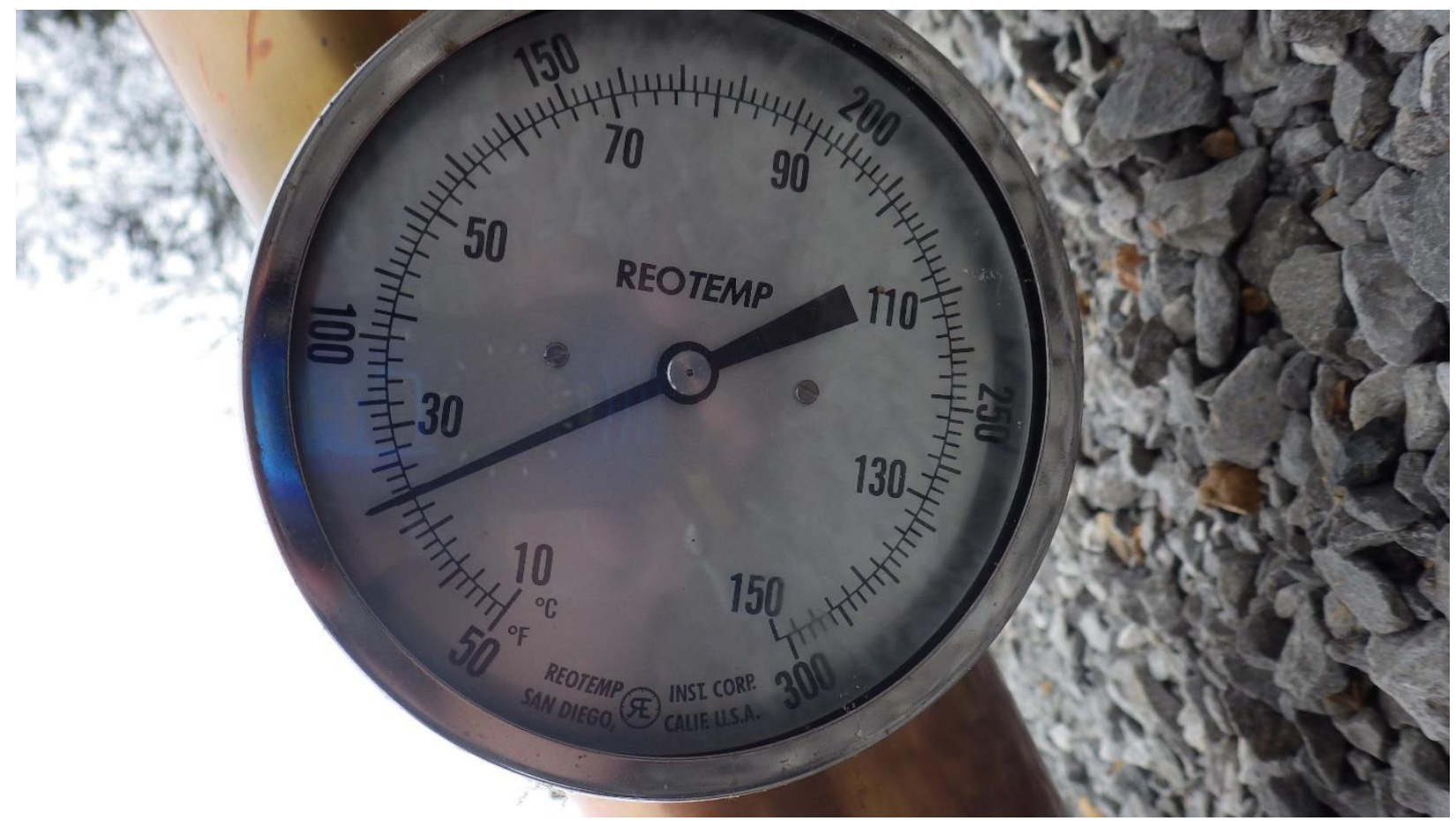

Photo \#4: The temperature gauge on the column. (Photo courtesy of the State Fire Marshall) 


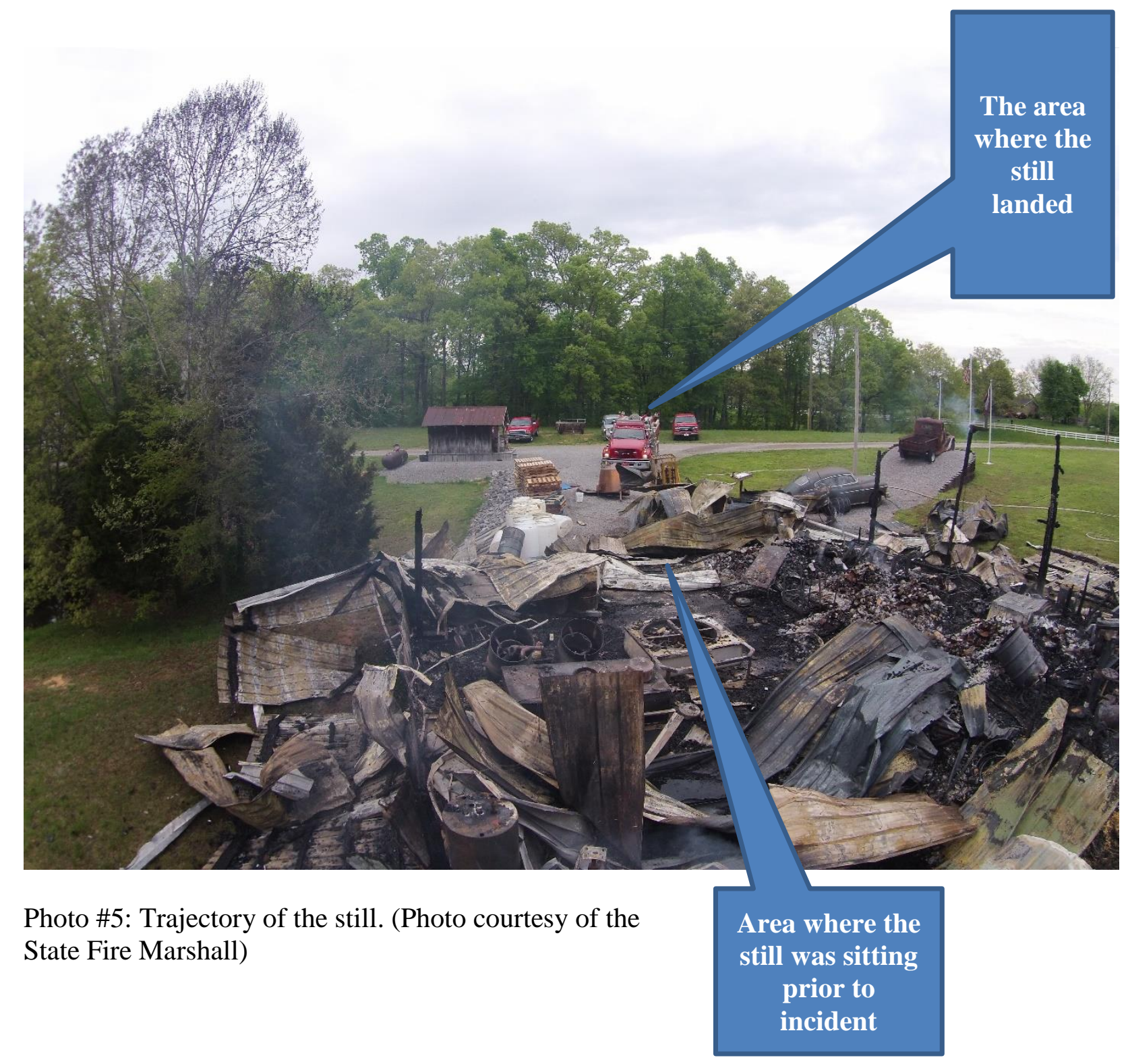

